\title{
Novel nanomaterials to stabilise the canvas support of paintings assessed from a conservator's point of view
}

\author{
Marta Oriola-Folch * (1), Gema Campo-Francés (1), Anna Nualart-Torroja (10, Cristina Ruiz-Recasens (1) \\ and Iris Bautista-Morenilla (1)
}

\begin{abstract}
During conservation treatment, consolidants and deacidifying agents can be added to the canvas of a painting to mechanically stabilise it and counteract the acidity that promotes degradation. In this study, new stabilising consolidants and deacidifying agents based on different nanoparticles (silica, calcium carbonate, magnesium oxide, cellulose nanofibrils and cellulose nanocrystals) were tested in comparison to traditionally used products. These products were applied onto different types of canvasses, and colour, gloss and pH changes were analysed. Conservators' subjective perceptions on the ease of application and the final visual results of the products were also assessed. Specifically, conservators were asked to examine the drying time and the ease of use of the products, as well as any changes in stiffness, darkening or whitening caused by the products on the canvasses. The best products were the ones based on calcium carbonate, magnesium oxide and cellulose nanocrystals. Cellulose nanofibrils are also promising consolidants because they are highly compatible with the chemical nature of painting canvasses.
\end{abstract}

Keywords: Nanoparticles, Conservation, Paintings, Canvas, Consolidation, Deacidification, Star diagram, pH, Colour, Gloss

\section{Introduction}

The canvas of paintings is composed of organic vegetable fibres that degrade over time, weakening the support [1]. This can lead to accidental tears in the painting, which then need to be repaired [2]. Before reaching this point, a strengthening agent can be applied to the verso of the painting, onto the canvas, in order to consolidate it [3]. Deacidifying agents can also be added to delay degradation by counteracting the acidity that promotes chemical degradation, which is often present in textiles [4]. To obtain a double effect, these two types of stabilising products can be applied simultaneously in a single step if they are miscible or in two separate applications if not.

*Correspondence: martaoriola@ub.edu

Department of Arts and Conservation, Faculty of Fine Arts, University of Barcelona, Barcelona, Spain
The first canvas consolidants were applied in the seventeenth century, when the support of the first oil paintings started to show signs of decay some 150 years after their production. These consolidants included animal glues, oils and resins [5].

Between the seventeenth and twentieth centuries, lining treatments (adhering a new canvas to the back of a painting) gained popularity and were carried out more and more frequently until 1974, when the famous Comparative Lining Techniques Conference held in Greenwich imposed a moratorium on the amount of linings being performed [6].

Nowadays, minimal possible intervention continues to be standard in the field of cultural heritage conservation [7]. In this regard, consolidating the canvas when needed can be less invasive than lining. This practice is used in countries like Italy and France [8-10]. In
Springer Open

(c) The Author(s) 2020. This article is licensed under a Creative Commons Attribution 4.0 International License, which permits use, sharing adaptation, distribution and reproduction in any medium or format, as long as you give appropriate credit to the original author(s) and the source, provide a link to the Creative Commons licence, and indicate if changes were made. The images or other third party material in this article are included in the article's Creative Commons licence, unless indicated otherwise in a credit line to the material. If material is not included in the article's Creative Commons licence and your intended use is not permitted by statutory regulation or exceeds the permitted use, you will need to obtain permission directly from the copyright holder. To view a copy of this licence, visit http://creativeco mmons.org/licenses/by/4.0/. The Creative Commons Public Domain Dedication waiver (http://creativecommons.org/publicdomain/ zero/1.0/) applies to the data made available in this article, unless otherwise stated in a credit line to the data. 
Spain, consolidation is not a very common intervention, although there are reports of its use in the literature [11].

Extensive research has been performed on the different types of adhesives used in conservation [12-16]. However, there are only few studies on the specific topic of canvas consolidation. For this reason, the Nanorestart project sent out an online survey to conservation centres throughout Europe. This questionnaire received 67 replies, of which 24 indicated that the following adhesives were used for canvas consolidation (in order of prevalence): Beva 371, Paraloid B72, Plexisol P550, Aquazol 200, animal glue, polyamide, Acryl 33, Lascaux 498 HV and Akeograd AT35. These replies were partially confirmed by the scarce references on the topic: Beva 371 $[3,8,9,17]$, acrylic resins $[3,8]$, animal glue $[8,10]$, and Akeograd AT35 (the old Purbinder) $[8,11]$.

Deacidification of cellulosic materials was first developed in the field of paper conservation. A large amount of research on the degradation process of cellulose and deacidification systems has been conducted since the 1930 s [18-23]. Deacidifying agents have included aqueous solutions of bicarbonates or hydroxides (often calcium hydroxide, magnesium bicarbonate and calcium bicarbonate), gaseous treatments based on diethyl zinc, and commercial products that are often solvent-based, such as Wei t'O, CSC Book Saver, Papersave or Bookkeeper, which contain particles such as magnesium oxide, magnesium hydroxide and others [23-25].

Since canvas is also a cellulose-based material, concerns about acidification appeared in the late twentieth century in England and the US [10, 26]. Painting conservators, however, seem to be slightly reluctant to adopt deacidifying treatments, probably because they feel that more research is needed regarding the possible migration of the added products up to the paint layer.

Nanoparticles are very small and therefore offer a larger amount of surface for chemical reactions to take place [27]. This is especially interesting in the field of conservation as the same result can be achieved with smaller amounts of the added product, thereby conforming to one of the main conservation principles of limiting treatment to what is strictly necessary [28].

Research on nanoparticle-based products and deacidification has increased exponentially this century [4, 29, 30]. In fact, several nanomaterials already exist on the market such as Nanorestore Paper ${ }^{\circledR}$ (based on calcium hydroxide), which can be used both for paper and for canvas deacidification [4].

This paper presents an assessment of the new products containing different types of nanoparticles (silica, calcium carbonate, magnesium oxide, cellulose nanofibrils and cellulose nanocrystals) developed through the Nanorestart project. These new products for consolidating and deacidifying canvasses were tested regarding colour, gloss and $\mathrm{pH}$, and were also compared to a selection of benchmark products. Furthermore, subjective observations of conservators regarding the application of the products (drying time of the product and ease of application) and the visual changes imparted on the canvas (stiffness and darkening/whitening) were recorded. The conservators' opinions are important because if they consider that a product lacks good handling properties or has undesired effects on the object, they will not use it. These same new nanoparticle-based products have also been tested by other researchers regarding aspects such as mechanical improvement and deacidifying capacity [31-34].

\section{Materials and methods}

\section{Products tested}

New strengthening and deacidifying products based on nanofibres and nanoparticles from three different institutions were tested at the University of Barcelona (UB). The products were from: Chalmers University of Technology (CUT, Gothenburg, Sweden), the Consorzio Interuniversitario per lo Sviluppo a Grande Interfase (CSGI, Florence, Italy) and the Zentrum für Bucherhaltung $\mathrm{GmbH}$ (ZFB, Leipzig, Germany).

The following is a description of the products tested from each of these three institutions (see Table 1 for the exact compositions of the materials).

\section{CUT products}

CUT produced three water-based consolidants: CUT I (+) and CUT II (-), which are nanosilica-based and consolidate at the fibre level (numbers 1 and 2 in Table 1 , respectively), and CUT CNF (number 3 in Table 1), which contains cellulose nanofibrils and consolidates at the thread level (the consolidant stays more on the surface of the canvas) [33].

Both CUT I $(+)$ and CUT II $(-)$ contain the colloidal silica Levasil CS40-213b (spherical diameter of $21 \mathrm{~nm}$ ), obtained from AkzoNobel Pulp and Performance Chemicals in Sweden, as well as branched polyethylenimine (PEI) (average molecular weight of $25,000 \mathrm{~g} / \mathrm{mol}$ ), obtained from Sigma-Aldrich. CUT II (-) has a second added layer of the sodium carboxymethyl cellulose (CMC) Akucell AF0305 (average molecular weight of 650,000 g/mol), obtained from AkzoNobel Pulp and Performance Chemicals in Sweden.

CUT CNF is composed of cellulose nanofibrils (CNF) provided by Stora Enso AB (Sweden) in the form of an aqueous dispersion of $3.3 \mathrm{wt} \%$. Further details on these materials and products are described elsewhere [32]. 
Table 1 List of all the products and combinations of these that were tested

\begin{tabular}{|c|c|c|c|c|}
\hline Number & Short name of the products & Contents & Main role & Solvent \\
\hline \multicolumn{5}{|c|}{ CUT products } \\
\hline 1 & CUTI (+) & $\begin{array}{l}\text { Silica* }\left(\mathrm{SiO}_{2}\right)+\text { polyethylenimine (PEI) at 2\% in water (dry } \\
\left.\text { material proportions: } \mathrm{SiO}_{2} 91.7 \% \mathrm{wt}, \mathrm{PEl} 8.3 \% \mathrm{wt}\right)\end{array}$ & Consolidant & Water \\
\hline 2 & CUT II (-) & $\begin{array}{l}\text { Silica* }\left(\mathrm{SiO}_{2}\right)+\text { polyethylenimine }(\mathrm{PEI})+\text { carboxymethyl } \\
\text { cellulose (CMC) at 2\% in water (dry material proportions: } \\
\mathrm{SiO}_{2} 91.7 \% \text { wt, PEl 0.2\% wt, CMC 8.3\% wt) }\end{array}$ & Consolidant & Water \\
\hline 3 & CUT CNF & Cellulose nanofibrils* (CNF) (1\% wt) & Consolidant & Water \\
\hline \multicolumn{5}{|c|}{ CSGI products } \\
\hline 4 & CSGII (+) & $\begin{array}{l}\text { Calcium carbonate* }\left(\mathrm{CaCO}_{3}\right)(2 \% \mathrm{wt})+\text { polyethylenimine } \\
(\mathrm{PEI})(0.05 \% \mathrm{wt})\end{array}$ & Deacidifying and consolidant & Water/ethanol \\
\hline 5 & CSGI II (-) & $\begin{array}{l}\text { Calcium carbonate }\left(\mathrm{CaCO}_{3}\right)(2 \% \text { wt })+\text { polyethylenimine } \\
(\mathrm{PEI})(0.05 \% \text { wt })+\text { carboxymethyl cellulose (CMC) }(0.4 \% \\
\text { wt) }\end{array}$ & Deacidifying and consolidant & Water/ethanol \\
\hline 6 & CSGI nanoP & Calcium carbonate* $\left(\mathrm{CaCO}_{3}\right)(2 \%$ wt $)$ & Deacidifying & Ethanol \\
\hline \multicolumn{5}{|c|}{ Combination of CUT and CSGI products } \\
\hline 7 & CUTI (+) and CSGI I (+) & CUTI $(+)$ mixed with CSGI I (+) 1-step process (2 products) & Deacidifying and consolidant & Water/ethanol \\
\hline 8 & CUT $\|(-)$ and CSGI $\|(-)$ & $\begin{array}{l}\text { CUT II (-) mixed with CSGI II (-) 1-step process (2 prod- } \\
\text { ucts) }\end{array}$ & Deacidifying and consolidant & Water/ethanol \\
\hline 9 & CUTI $(+)$ and CSGI I (+) + CNF & $\begin{array}{l}\text { CUT I (+) mixed with CSGI I (+) Once dry, CNF on top } \\
\text { 2-step process (3 products) }\end{array}$ & Deacidifying and consolidant & Water/ethanol \\
\hline 10 & CUT II (-) and CSGI II (-) + CNF & $\begin{array}{l}\text { CUT II (-) mixed with CSGI II (-) Once dry, CNF on top } \\
\text { 2-step process (3 products) }\end{array}$ & Deacidifying and consolidant & Water/ethanol \\
\hline \multicolumn{5}{|c|}{ ZFB products } \\
\hline 11 & ZFB $1 \mathrm{a}$ & Calcium carbonate* $\left(\mathrm{CaCO}_{3}\right)$ (3 wt\%) & Deacidifying & Water \\
\hline 12 & ZFB 1b & $\begin{array}{l}\text { Hydroxyethyl methyl cellulose (HEMC) (1.86 wt\%) + cellu- } \\
\text { lose nanocrystals* (CNC) (0.088 wt\%) }\end{array}$ & Consolidant & Water \\
\hline 13 & ZFB 1C & $\begin{array}{l}\text { Hydroxyethyl methyl cellulose (HEMC) }(1.86 \text { wt\%) + cellu- } \\
\text { lose nanocrystals* (CNC) (0.088 wt } \%)+ \text { calcium carbon- } \\
\text { ate }\left(\mathrm{CaCO}_{3}\right)(3 \text { wt } \%)\end{array}$ & Deacidifying and consolidant & Water \\
\hline 14 & ZFB 2a & Magnesium oxide* (MgO) (1 wt\%) & Deacidifying & Heptane \\
\hline 15 & ZFB 2b & $\begin{array}{l}\text { Hydroxyethyl methyl cellulose (HEMC) }(1.86 \text { wt\%) + cellu- } \\
\text { lose nanocrystals* (CNC) (0.088 wt\%) }\end{array}$ & Consolidant & Heptane \\
\hline 16 & ZFB 2C & $\begin{array}{l}\text { Hydroxyethyl methyl cellulose (HEMC) }(1.86 \text { wt } \%)+\text { cel- } \\
\text { lulose nanocrystals* (CNC) (0.088 wt } \%)+ \text { magnesium } \\
\text { oxide* }(1 \text { wt } \%)\end{array}$ & Deacidifying and consolidant & Heptane \\
\hline \multicolumn{5}{|c|}{ Benchmark consolidants and deacidifying products } \\
\hline 17 & Beva $^{\circledR} 371$ & Beva $^{\circledR} 371$ (6\% wt) & Consolidant & Cyclohexane \\
\hline 18 & Paraloid B72 & Paraloid B72 (5\% wt) & Consolidant & Acetone \\
\hline 19 & Animal glue & Animal glue (5\% wt) & Consolidant & Water \\
\hline 20 & Nanorestore Paper ${ }^{\circledR}$ & Nanorestore Paper ${ }^{\circledR}$ Ethanol $3^{*}$ & Deacidifying & Ethanol \\
\hline
\end{tabular}

The asterisks indicate nano-sized particles

\section{CSGI products}

CSGI provided three deacidifying agents, two of these (CSGI I $(+)$ (number 4 in Table 1 ) and CSGI II (-) (number 5 in Table 1) were provided in a water/ethanol mixture, while CSGI nanoP (number 6 in Table 1) was $100 \%$ ethanol-based.

As CSGI II (-) contains a deacidifying agent and a cellulose derivative, it is better for providing mechanical strength to the canvas than CSGI I (+).
Calcium carbonate nanoparticles were used at a concentration of about $2 \%$ in ethanol (CSGI nanoP). CSGI I $(+)$ was prepared by mixing calcium carbonate nanoparticles in ethanol with PEI (0.05\%) and adding water to obtain an ethanol/water mixture of about $45 \%$ vol. CSGI II (-) was obtained by adding CMC $(0.4 \%)$ to CSGI I (+).

A solvothermal process starting from calcium metal and ethanol has been recently proposed for the preparation of calcium hydroxide nanoparticles [35]. A 
modification of this process, based on the use of water and diethyl carbonate to convert calcium ethoxide into calcium carbonate, was used to prepare calcium carbonate nanoparticles. Branched PEI with an average molecular weight $\left(\mathrm{M}_{\mathrm{w}}\right)$ of $25,000 \mathrm{~g} / \mathrm{mol}$ was purchased from Sigma-Aldrich. Sodium CMC supplied by Nouryon, Bohus, Sweden (formerly AkzoNobel Pulp and Performance Chemicals) had a degree of substitution of 0.77 and a viscosity of $12 \mathrm{mPa} s$ (at $1 \%$ ). The Mw of the CMC was $650,000 \mathrm{~g} / \mathrm{mol}$ (determined by size exclusion chromatography).

\section{Combination of CUT and CSGI products}

CUT and CSGI designed products that could be mixed together. CUT I $(+)$ can be mixed with CSGI I $(+)$ (number 7 in Table 1) and CUT II (-) can be mixed with CSGI II (-) (number 8 in Table 1). This enables the application of a deacidifying agent and a consolidant (at the fibre level) in a one-step process.

After applying the mixture of CUT I (+) and CSGI (+) or CUT (-) and CSGI (-), a nanocellulose-based consolidant (CUT CNF) can then be added if desired for further consolidation (numbers 9 and 10 in Table 1). This would entail the application of three products in a twostep process.

\section{ZFB products}

Six products were developed by ZFB. Two of them were deacidifying agents (a calcium carbonate-based one in water (ZFB 1a, number 11 in Table 1) and a magnesium oxide-based one in heptane (ZFB 2a, number 14 in Table 1)) and two of them were nanocellulose-based consolidants (one in water (ZFB 1b, number 12 in Table 1) and one in heptane (ZFB 2b, number 15 in Table 1)).

The remaining two products were mixtures of the abovementioned deacidifying agents and consolidants. One of them was a mixture of the two water-based products (ZFB 1c, number 13 in Table 1) and the other one was a mixture of the two heptane-based products (ZFB 2c, number 16 in Table 1).

The deacidifying agents, ZFB 1a and ZFB 2a, were developed and produced by ZFB and are sub- $\mu \mathrm{m}$ dispersions in water and heptane, which means that the calcium carbonate and magnesium oxide used have a particle size of under $1 \mu \mathrm{m}$ [34].

The consolidants ZFB 1b, ZFB 2b, ZFB 1c and ZFB 2c contain hydroxyethyl methyl cellulose (Tylose ${ }^{\circledR} \mathrm{MH}$ ), purchased from Shin Etsu, and cellulose nanocrystals (CelluForce $\mathrm{NCC}^{\mathrm{TM}}$ ), obtained from CelluForce Inc. For the solvent-based products, a silylation reaction was carried out [34].

\section{Traditionally used benchmark products}

For comparison, three consolidants and one deacidifying agent that are currently used by conservators (see the Introduction section) were also assessed: Gustav Berger's Original Formula ${ }^{\circledR} 371$ (Beva $^{\circledR}$ 371) from CTS Srl (number 17 in Table 1); Paraloid B72 from CTS Srl (number 18 in Table 1); animal glue from Lienzos Levante (Spain; number 19 in Table 1) and Nanorestore Paper ${ }^{\circledR}$ Ethanol 3 from CSGI (number 20 in Table 1).

\section{Supports used for testing the products}

The products were tested on four different types of canvas supports.

Two of them were new textiles: linen canvas, provided by Lienzos Levante (Valencia, Spain; reference number 20) with a grammage of $200 \mathrm{~g} / \mathrm{m}^{2}$, and cotton canvas, obtained from Barna Art (Barcelona, Spain) and with a grammage of $417 \mathrm{~g} / \mathrm{m}^{2}$.

The third type of support was an artificially degraded jute canvas from Lienzos Levante (Valencia, Spain; $300 \mathrm{~g} / \mathrm{m}^{2}$ ). Degradation was achieved by immersing the canvas into $1 \% \mathrm{w} / \mathrm{w}$ of an alum solution prior to tacking it onto a stretcher (once it was dry). Then, one layer of animal glue $(9.6 \% \mathrm{w} / \mathrm{v})$ was applied onto the canvas. Once the glue was dry, samples were cut and placed in an oven (Heraeus Voetsch $\mathrm{HC} 0020$ ) at $90{ }^{\circ} \mathrm{C}$ and $65 \%$ relative humidity ( $\mathrm{RH})$ for 18 days [36]. The $\mathrm{pH}$ of the degraded samples was 3.9.

Finally, products were also applied onto a sacrificial real painting: "Landscape" from ca. 1950. The grammage of this canvas is unknown, but based on experience with other known grammage, it was thought to be around $200 \mathrm{~g} / \mathrm{m}^{2}$. The canvas has a light brown tonality and a $\mathrm{pH}$ of 5.4.

\section{Application method and amount of product applied}

All the products were applied onto the canvas samples using a brush so that the amount of product deposited could be quantified. On real paintings, products are added to the back of the painting, onto the original canvas, and are sprayed if the conservator prefers not to wet the painting excessively.

The amount of product applied resulted in a " $5 \%$ weight increase" in all cases with regard to the weight of the untreated canvas. Accordingly, coarser canvasses received more product than lighter ones.

This rule was not followed for the CSGI products, since the guidelines indicated that " $1 \mathrm{~mL}$ of product for each $20 \mathrm{~cm}^{2}$ of canvas" should be used for CSGI I (+), CSGI II (-) and CSGI nanoP. This causes a " $5 \%$ weight increase" in the case of canvasses with a grammage 
of $200 \mathrm{~g} / \mathrm{m}^{2}$ (which is quite a common grammage for regular paintings). The instructions for Nanorestore Paper ${ }^{\circledR}$ Ethanol $3^{*}$ stated that $2 \mathrm{~mL}$ should be applied for each $20 \mathrm{~cm}^{2}$.

\section{Colour analysis}

Colour was measured for each sample at three different spots, with L, a and b values for the SCI (Specular Component Included) recorded using the CIELab76 system.

The instrument used was a Konika Minolta CM-26000d spectrophotometer. The aperture was set at $0.8 \mathrm{~mm}$ (the larger option) and a minimum of three measurements were taken at each spot. If the SD of either $\mathrm{L}$, $\mathrm{a}$ or $\mathrm{b}$ was larger than 0.3, up to seven measurements were taken.

Melinex films with pen marks were used to relocate the instrument onto the same place after treatment to ensure that the same spots were measured. The same pile of white paper was placed under the canvas when taking the measurements to make sure that the background was the same for all measurements.

The conditions of the instrument were set at: mask/ gloss, M/I + E; UV, 100\%; Il.1, D65; Il.2, -; observer, 10; display, Diff\&ABS; colour space, L*a*b*; manual avg. times, -; auto avg., 3 ; and delay time, $0.5 \mathrm{~s}$.

\section{Gloss analysis}

A Rhopoint Novo-Gloss glossmeter was used to measure gloss before and after treatment on the new linen canvas. Each sample was measured at three locations and each location was measured three times. Since matt surfaces were being measured and given that the values obtained with the $60^{\circ}$ angle were below $10 \mathrm{GU}$, results obtained with the $85^{\circ}$ angle were the ones that were recorded (as is normally done) [37].

Pencil marks on the samples and a plastic template from the instrument were used for repositioning the instrument onto the same place after treatment.

\section{$\mathrm{pH}$ analysis}

The $\mathrm{pH}$ was measured through the $\mathrm{pH}$ cold extraction method using an IQ160 $\mathrm{pH}$ meter with a pHW17-SS ISFET micro-probe both on the acidic jute canvas and on the sacrificial real painting.

Samples were taken using a scalpel and tweezers. The size of the sample obtained was about $4 \mathrm{~mm}$ of a thread for the sacrificial painting and about $2 \mathrm{~mm}$ for the jute canvas (jute threads are coarser, thus less sample is needed). This length of the threads was found to correspond to the 250-350 $\mu$ g required for the miniaturisation of TAPPI 509 om-02 pH [38]. $100 \mu \mathrm{L}$ of distilled water were added to the vial containing the sample and $\mathrm{pH}$ measurements were taken the day after the sample was immersed in water.

Three samples were taken from each of the systems analysed and each sample was measured three times.

\section{Star diagram}

A table with five different items was designed so that conservators could evaluate the application of the products on linen and their visible results. This was a subjective type of evaluation, where conservators compared their experience of the new products with that of the materials they have already used in conservation. The quantification of the mechanical improvement and of the deacidifying ability of the products has been analysed elsewhere [31-34].

The items evaluated were:

1. Drying time of the product

2. Ease of use

3. Stiffness of the treated canvas

4. Colour change of the canvas: darkening

5. Colour change of the canvas: whitening

For each evaluated item, three different possible values were established, 1 being the worst score and 3 being the best. For each item, a reference sample for each of the two extreme values, 1 and 3, was established and all the samples were then rated against these. The information was then plotted in star diagrams, making it easier to visually identify the products with the best results (those with a larger surface of the star covered) in terms of the items evaluated.

The star diagram evaluation was carried out by the UB conservators participating in the Nanorestart project on linen samples. The fourteen different single products were evaluated, leaving aside the treatments requiring two layers or mixtures (systems $7,8,9,10,13$ and 16). The following is a description of how each item was evaluated and the meaning of each given value.

\section{Drying time of the product}

Water-containing products pose a risk to materials such as the canvas or ground layers by causing swelling or shrinking [39]. In the case of solvent-based products, prolonged contact with solvents can create swelling or leaching of the paint layers and varnishes $[3,40]$. Therefore, to avoid adverse consequences resulting from prolonged contact, products with shorter drying times are preferred.

The drying times of the different products were assessed. A score of 1 was given to samples with drying 
times similar to that of animal glue, which is waterbased and takes about $20 \mathrm{~min}$ to fully dry (visually). A score of 3 was given to products that took less than a minute to dry fully, while a score of 2 was given to products that took between 1 and 20 min to dry.

\section{Ease of use}

The ease with which a product can be applied is quite often an important factor when deciding which product to use in a particular situation.

Products rated as 1 were those that had some properties that made them more cumbersome to use, such as high viscosity, which made it difficult to spray them, or the need to constantly shake the product well before application to avoid the particles from settling.

A score of 2 was given to products that required specific equipment such as a fume hood due to the toxicity of their solvents or other special requirements, while a score of 3 was given to products that were easy to use and did not need complicated preparations or equipment.

\section{Stiffness of the treated canvas}

The capacity of the products to improve the stiffness of the canvas was evaluated by determining if the added products improved resistance to the elongation of the canvas.

The canvas (with the added products) must support the ground and paint layers and limit the movements of these rigid layers to avoid permanent deformation that occurs long before the formation of cracks [33].

Stiffness can be improved either by locking the threads (interlocking weft and warp) with a layer of product that reinforces the canvas or by reinforcing threads and fibres onto a deeper level.

Samples treated with the different products were assessed by pulling the canvas in the weft, warp and diagonal directions to check the deformation of the treated canvas according to the different tensions that occur in a painting and in order to see the reinforcement of the whole.

A score of 3 was given to samples that, under tension, moved very slightly, as was observed with product 3 (CNF). A score of 1 was given to samples that, under tension, moved as much as the untreated linen. Finally, a score of 2 was given to samples in which a slight reinforcement was detected, and which fell between those rated as close to 1 and those rated as close to 3 .

\section{Colour change of the canvas: darkening}

Ideally, any product added onto the canvas of a painting should not alter its original visual appearance. This is because even if the canvas side is never exposed when viewing the painting, the main conservation principle of introducing minimal changes into the object needs to be followed [7]. This being said, it is also true that a compromise between a small colour change and an improvement in the canvas condition (mechanically or regarding acidity levels) might be needed since the latter can be of greater importance.

Colour change in terms of darkening caused by the treatments was assessed by visually looking at the samples from a distance of $1.5 \mathrm{~m}$ and comparing the overall darkening of the linen sample with that of the untreated linen sample (score of 3 ) and also of the animal gluetreated sample (which had a score of 1 since this was the sample that darkened the most). A score of 2 was given to samples that were between those rated as close to 1 and those rated as close to 3 and therefore had some degree of darkening, but one that was acceptable.

\section{Colour change of the canvas: whitening}

Whitening caused by the treatments was assessed by visual inspection of the samples from a distance of $1.5 \mathrm{~m}$ and comparing the overall whitening of the linen sample with that of the untreated sample (score value of 3 ) and also of the sample treated with product combination 9 (the one that received one coat of CUT I $(+)$ and CSGI I (+) plus a CNF coat on top), which was perceived to be too whitened (score value of 1 ). A score of 2 was given to samples that fell between the other two categories (some whitening, but acceptable).

\section{Results and discussion Colour change}

Colour was measured before and after the application of the products on all four types of support: linen, cotton, jute and a sacrificial painting. Delta $\mathrm{E}_{\mathrm{ab}}^{*}$ was calculated using $\mathrm{L}^{*}, \mathrm{a}^{*}$ and $\mathrm{b}^{*}$ values before and after application to assess the general change in the colour of the canvas when the different products were applied (see Fig. 1).

All products produced some sort of colour change, which was acceptable in most of the cases. Values above 3.5 indicate that a "clear difference in colour is noticed" [41]. Many of the products produced values below this.

However, some of the new products such as 9 and 16 produced noticeable colour changes.

Since the products applied are either transparent or whitish, differences between the $\mathrm{L}$ values before and after application were also assessed ( $\mathrm{L}$ is the white-dark axis) (see Fig. 2).

All the three traditional consolidants tested darkened the canvas. The nanoparticle-based products that tended to whiten the canvas were mostly deacidifying products 


\section{Delta $\mathrm{E}_{\mathrm{ab}}$ * change after application and SEM error bars}

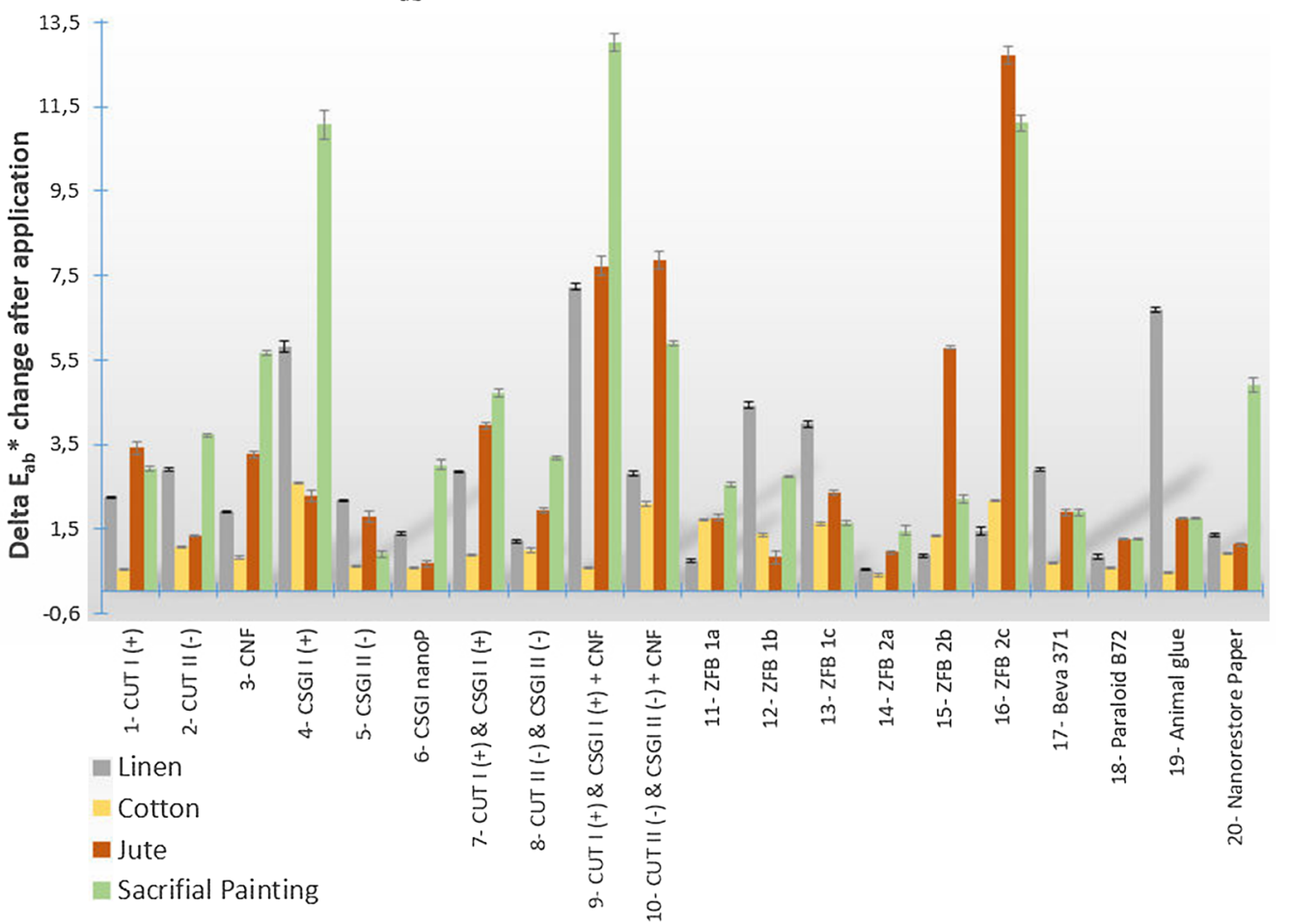

Fig. 1 Delta $E^{*}$ results and standard error mean bars $(S E M=S D / \sqrt{ } n)$, using Student's t-distribution for paired variables $(n=9$ or 12 according to the hypothesis contrast tests), after the application of the products onto different types of support (linen, cotton, jute and sacrificial painting)

and CNF or combinations of products that included a deacidifying agent. The product combination 9, for instance, showed a whitening effect in three of the four types of canvasses tested.

Regarding the CUT products, the two consolidants at the fibre level (CUT I $(+)$ and CUT II $(-)$ ) tended to slightly darken the canvas, whereas CNF whitened it quite considerably.

In the case of the CSGI products, CSGI I (+) whitened the support a bit too much, but the other two products (CSGI II (-) and CSGI nanoP) produced better results in this regard.

Heptane-based ZFB products tended to whiten the canvas more than its water-based counterparts. The mixture of a deacidifying agent plus a consolidant in heptane produced a bit too much whitening, especially in darker supports (ZFB 2c). This difference could be due to the fact that the heptane solvent evaporates very rapidly, leading the products to remain on the surface longer than their water-based counterparts.

The whitening effect is more of a problem with dark canvasses, since all the products could be applied to the white cotton canvas without problem. Therefore, non-whitening products and combinations would be more appropriate for dark supports.

Curiously, in a few instances, the whitening or darkening effect of the product depended on the type of canvas. This was especially noticeable for product combination number 7 , where the mixture of CUT I $(+)$ and CSGI $(+)$ slightly whitened the sacrificial painting and linen canvas, but darkened the jute canvas considerably. Thus, it is strongly advisable to perform a small test before applying any product to a whole canvas.

\section{Gloss changes}

Gloss was measured before and after treatment on the linen canvas. The average $\mathrm{GU}$ of the linen canvas before treatment was 0.76 (SD 0.08). The higher the GU value, the glossier the surface is.

All products showed a slight matting effect on the linen canvas (which being new, had a slight lustre), except for ZFB 2c, which caused a very small increase in glossiness. The changes, however, were very small and were perfectly acceptable in all cases.

The product causing the largest change (matting effect) was CSGI (+), followed by CUT CNF. 


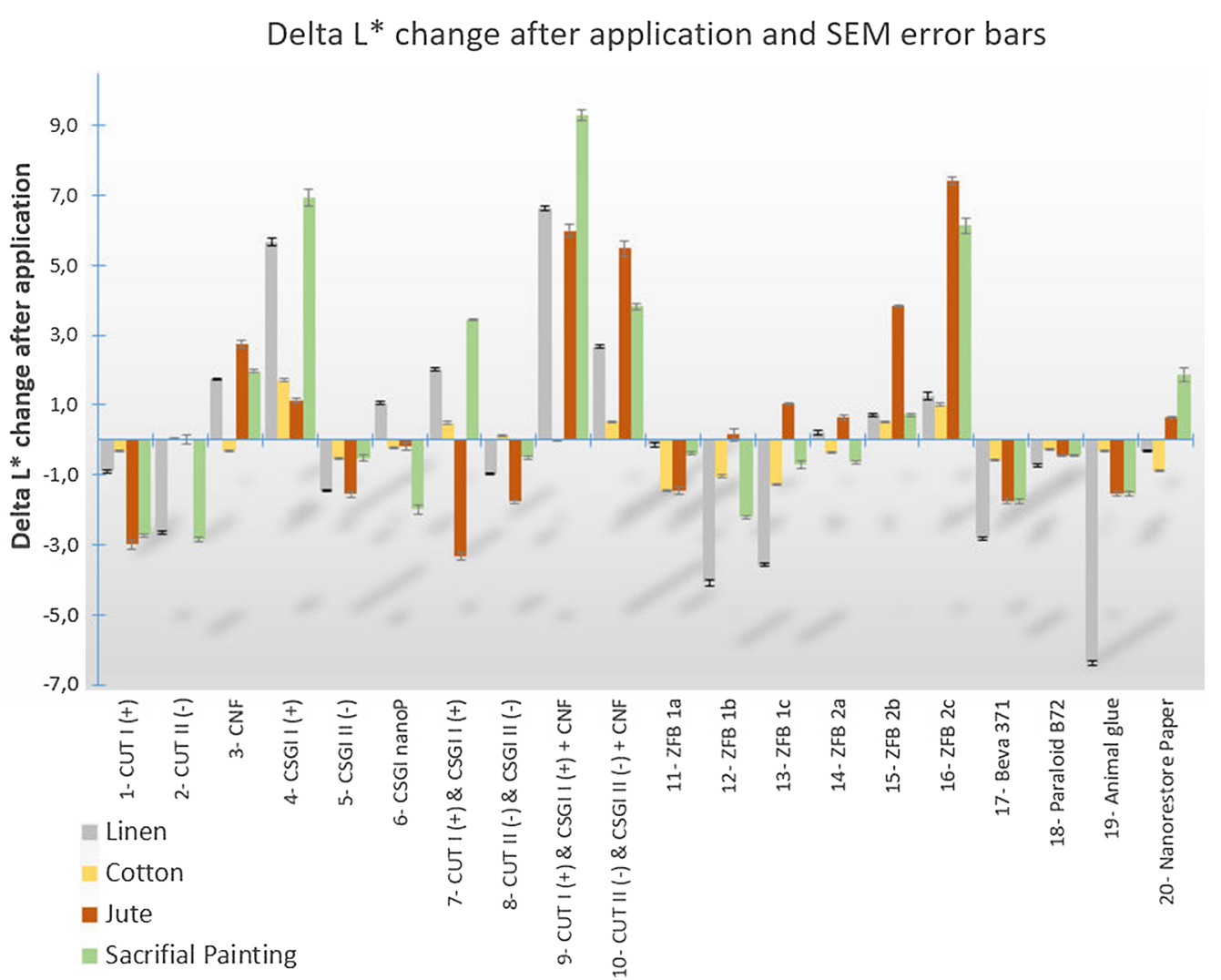

Fig. 2 Delta $L^{*}$ results and standard error mean bars $(S E M=S D / \sqrt{ } n$ ), using Student's t-distribution for paired variables ( $n=9$ or 12 according to the hypothesis contrast tests), after the application of the products. Positive values indicate a whitening effect of the treatment, while negative values indicate a darkening effect

Interestingly, when looking at the treated linen canvasses with the naked eye, the matting effect of the products was perceived as small and perfectly acceptable, whereas the relatively much smaller increase in glossiness caused by ZFB 2c was quickly spotted (although still acceptable). This probably indicates that the human eye is much more sensitive to glossier surfaces. In other words, a slight matting effect is barely perceptible and completely acceptable, whereas a much smaller increase in glossiness might be readily noticeable by the conservator.

ZFB 2b, which had a matting effect (see Fig. 3), was observed by the naked eye to have slightly increased the glossiness of the sample (to a similar degree as ZFB 2c). This could be explained by errors in the measurement, given that the error bars indicate that the real difference could be above zero, as is the case for ZFB 2c.

The slight increase in glossiness caused by ZFB $2 \mathrm{~b}$ and ZFB 2c could be due to the fast evaporation of the solvent (heptane) and the thick consolidant, causing the products to remain on the surface longer than their water-based counterparts.

\section{$\mathrm{pH}$ results}

The $\mathrm{pH}$ was measured only for the deacidifying products and only on the two acidic supports: the degraded jute canvas (the starting $\mathrm{pH}$ was 3.9) and the real painting (the starting $\mathrm{pH}$ was 5.4). The results obtained are shown in Table 2.

Looking at the jute canvas results, all three CSGI deacidifying agents performed very well both when applied on their own and when applied in combination with the CUT products, neutralising the $\mathrm{pH}$ of the acidic canvas. In fact, they performed better than the benchmark product (Nanorestore Paper ${ }^{\circledR}$ Ethanol 3).

In the case of the four ZFB products, the two mixtures of consolidant plus deacidifying agent did not counteract the acidity of the jute canvas. This might be because the consolidant was so viscous that there was an excessive accumulation of the product on the surface, and therefore the deacidifying agent was not able to penetrate the whole canvas.

Interestingly, despite the higher $\mathrm{pH}$ of the real painting before treatment (starting $\mathrm{pH}$ was 5.4 ), the $\mathrm{pH}$ values were very similar or even slightly lower than those 


\section{Gloss Change (GU) and confidence interval $95 \%$ in the t-Student distribution for paired variables with $\mathrm{t}_{0,025} 8=2,306$}

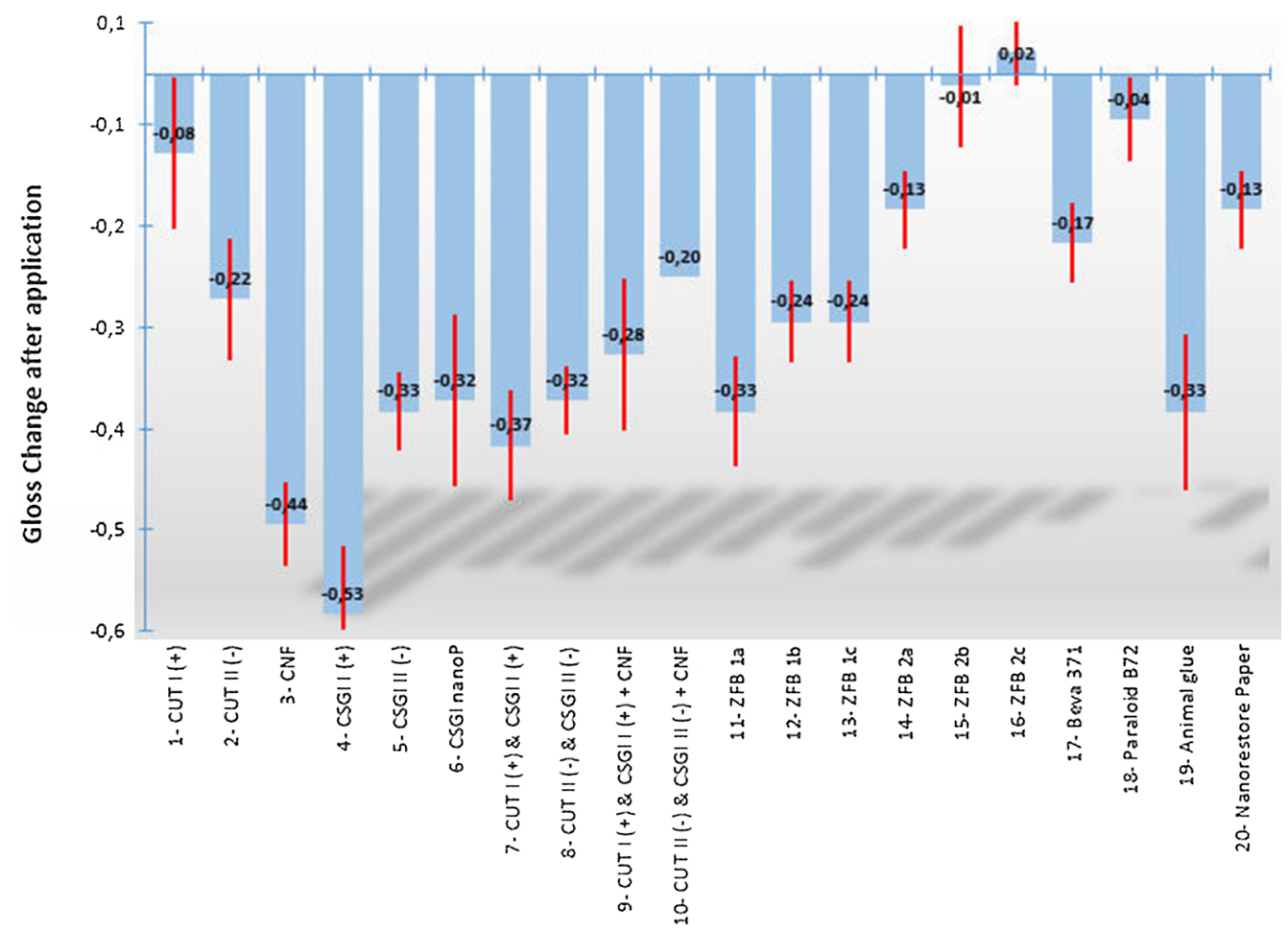

Fig. 3 Gloss change $(G U)$ and standard error mean bars $(S E M=S D / \sqrt{ } n)$, using Student's t-distribution for paired variables $(n=9)$, after product application. A negative value indicates that the surface has become less glossy (a bit more matt), while a positive value indicates that the surface has become glossier

Table $2 \mathrm{pH}$ values after treatment of the jute canvas and the real painting

\begin{tabular}{|c|c|c|c|}
\hline Number & Product & After treatment $\mathrm{pH}$ on jute canvas & $\begin{array}{l}\text { After treatment } \mathrm{pH} \\
\text { on sacrificial real } \\
\text { painting }\end{array}$ \\
\hline \multicolumn{4}{|c|}{ CSGI products } \\
\hline 4 & CSGII (+) & 7.7 & 6.7 \\
\hline 5 & CSGI\| (-) & 7.8 & 7.0 \\
\hline 6 & CSGI nanoP & 7.4 & 6.8 \\
\hline \multicolumn{4}{|c|}{ Mixtures of CSGI and CUT products } \\
\hline 7 & CSGI I (+) and CUTI (+) & 7.0 & 7.2 \\
\hline 8 & CSGI ॥ (-) and CUT ॥ (-) & 7.6 & 6.8 \\
\hline 9 & CSGI I (+) and CUTI (+) + CNF & 7.6 & 7.0 \\
\hline 10 & CSGI II (-) and CUT II (-) + CNF & 7.7 & 7.1 \\
\hline \multicolumn{4}{|c|}{ ZFB products } \\
\hline 11 & ZFB 1a & 7.0 & 6.4 \\
\hline 12 & ZFB 1C & 4.4 & 6.0 \\
\hline 14 & ZFB 2a & 8.0 & 7.3 \\
\hline 16 & ZFB 2C & 4.8 & 7.5 \\
\hline \multicolumn{4}{|c|}{ Benchmark deacidifying product } \\
\hline 20 & Nanorestore Paper ${ }^{\circledR}$ Ethanol 3 & 6.2 & 6.1 \\
\hline
\end{tabular}




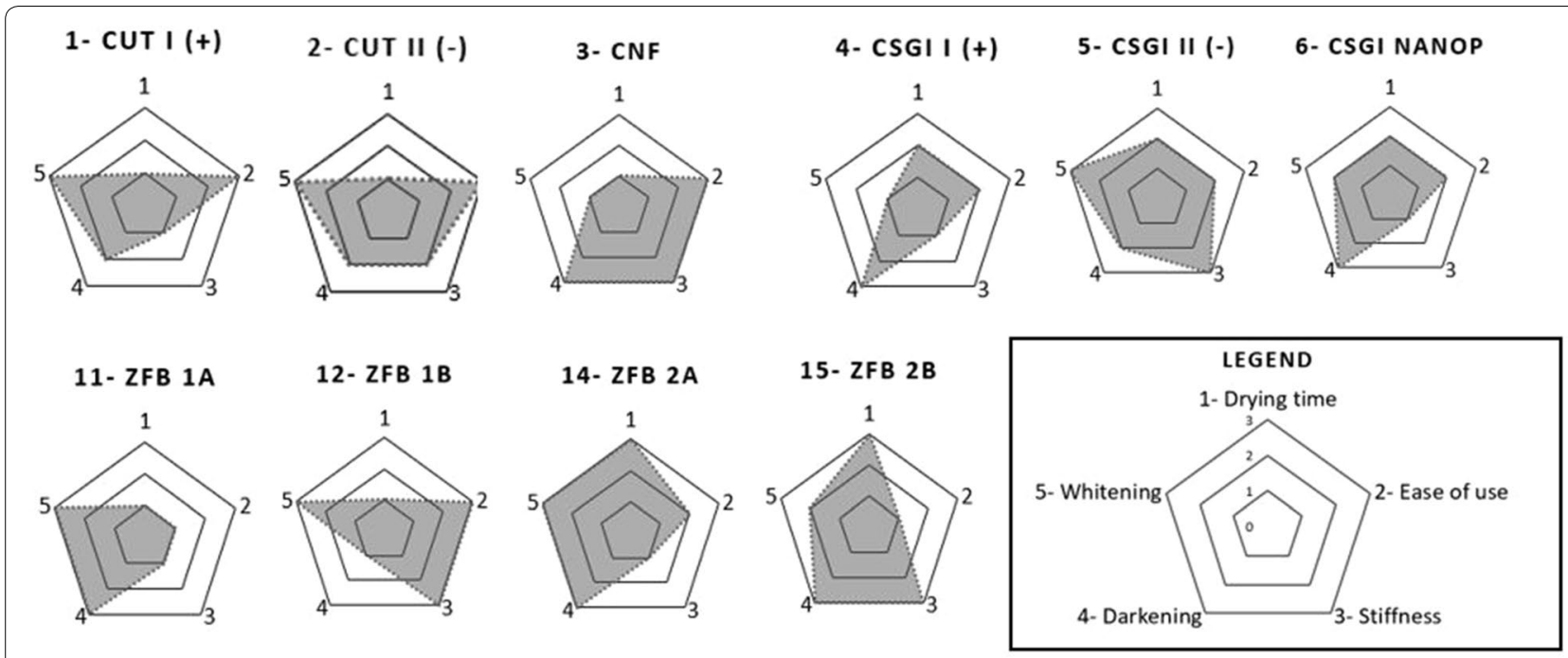

17- BEVA 371

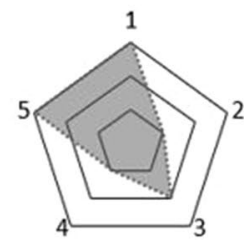

18- PARALOID B72

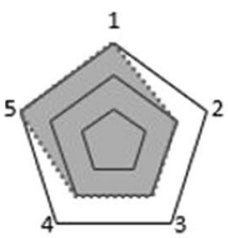

19- ANIMAL GLUE

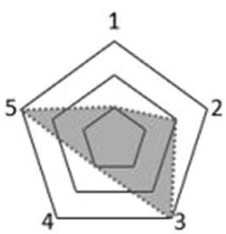

20- NANORESTORE PAPER

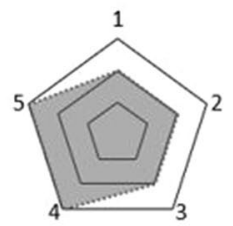

Fig. 4 Star diagrams for the fourteen products tested

of the acidic jute canvas after treatment. This difference could be explained by the heterogeneity of the products present on the real painting, which might include some materials acting as a barrier.

\section{Star diagram results}

Figure 4 presents the results of the conservators' subjective evaluation of the products regarding applicability and visual results.

In general, all the tested products had acceptable applicability and end visual results compared with the benchmark products (Beva ${ }^{\circledR}$ 371, Paraloid B72, animal glue and Nanorestore Paper $^{\circledR}$ Ethanol 3). These results indicate that all of them could potentially be incorporated into daily practice by conservators.

Drying time scores for the water-based products were suboptimal. This may represent a problem due to the risk of the canvas or ground layers swelling or shrinking. These effects can be avoided by spraying the products, although this prolongs application times (the amount of product applied with 1 brush layer may need up to 10 spray layers) and may reduce their penetration into the canvas structure (which will probably be less efficient in terms of consolidation/deacidification, but with higher reversibility). By contrast, all the solvent-based products scored well, ZFB $2 \mathrm{~b}$ having the fastest drying time.
Regarding ease of use, the traditional consolidant Beva 371 received a low score for practical reasons (e.g., it must be kept warm, it needs a fume hood, and the tools are not easy to clean). Two new products also presented low scores: ZFB $2 \mathrm{~b}$, due to its high viscosity that made it difficult to spray, and ZFB 1a, which had very rapidly settling particles. However, the other products tested scored well for ease of use, more than some of the benchmark products. Those with a score of 2 were solvent-based (thus requiring access to a fume hood) or required extra handling or special preparations, like animal glue.

In terms of stiffness, the products that scored the highest were CNF, CSGI II (-), ZFB 1b, ZFB 2b and animal glue. It should be borne in mind that the rigidity of some of the materials such as animal glue varies greatly with $\mathrm{RH}$. At $50 \% \mathrm{RH}$, which was the condition we used to test the products, animal glue showed considerable rigidity; but if $\mathrm{RH}$ rises to values close to $80 \%$, its resistance to stretching approaches zero, and at values under $40 \% \mathrm{RH}$ the glue contraction may cause permanent deformation of the ground and paint layers.

Compared to the benchmark products, four of the new products considerably improved the stiffness of the canvas, which is fundamental in guaranteeing good preservation of a painting. 
Interestingly, the results of the star diagram on darkening and whitening were completely in accordance with the analytical results obtained. The following products caused the most darkening on the linen canvas: animal glue, Beva 371 and ZFB 1b, which all scored 1 in the star diagram evaluation, followed by CUT II (-), CSGI II (-), CUT I (+) and Paraloid B72, which all scored 2. The rest of the products, with a score of 3 , were considered not to have a darkening effect.

When comparing the conservators' scores with the change in the L values obtained analytically (see Fig. 2), we observed that a product that caused quite visible darkening (score of 1) correlated with an L change of below -2.66 . Products that caused some darkening but to an acceptable level (score of 2) correlated with an L change of between -0.69 and -2.66 , while those that caused no visible change (score of 3 ) correlated with an L change of between -0.69 and 0 .

Regarding whitening, CSGI I (+) and CNF caused the most whitening on the linen canvas (score of 1), followed by CSGI NanoP and ZFB 2b, which caused some whitening, but to an acceptable degree (score of 2). The remaining products did not cause whitening.

Products that whitened the linen canvas a little bit too much (scored 1) correlated with an L change of above 1.06, those that scored 2 (i.e., caused some whitening, but to an acceptable degree) correlated with an L change of between 0.67 and 1.06, while those that caused no whitening (scored 3) correlated with an L change of below 0.67 .

In summary, the products with the best scores in relation to the five items evaluated were ZFB 2a, ZFB 2b and CSGI II (-), with scores similar to Paraloid B72 and Nanorestore Paper ${ }^{\circledR}$ (see Fig. 4).

\section{Conclusions}

Regarding colour changes, all the new products performed well on white cotton canvas. Most of them also performed well on darker canvasses (linen, jute and sacrificial painting), especially compared to the traditional consolidant animal glue, which darkened linen quite considerably. Some products had a greater whitening effect on dark canvasses than others. Therefore, when treating darker canvasses, products with a weaker whitening effect should be used, for instance, CSGI NanoP over CSGI I (+). However, it is advisable to always perform a small test prior to full application, since some product combinations had both whitening and darkening effects depending on the type of support used.

Regarding gloss, none of the products caused perceptible changes in the appearance of the canvas, with the exception of ZFB $2 \mathrm{a}$ and ZFB $2 \mathrm{~b}$, which caused a very slight increase in glossiness.
All the CSGI products tested had good deacidifying capacities. The ZFB deacidifying products (ZFB $1 \mathrm{a}$ and ZFB 2a) performed well too, but were not effective in raising the $\mathrm{pH}$ on jute canvasses when mixed with a consolidant (ZFB 1c and ZFB 2c), indicating that a twostep application should be performed with the deacidifying agent added first followed by the consolidant. The $\mathrm{pH}$ of the canvas should be measured at several different locations after treatment so that more product can be added if needed, since the high heterogeneity of real paintings can require different amounts of product in each particular case.

The evaluations of the conservators indicated that all the tested products could be incorporated into daily practice. Solvent-based products, which have a shorter evaporation time, reduce the risk of shrinking or swelling of the canvas and ground layers compared with waterbased products with longer evaporation times. However, solvent-based products may be less user-friendly due to the toxicity of the solvents. For water-based products, the issue of longer drying times could be overcome by spraying several thin coatings of the products.

CNF, ZFB 1b, ZFB 2b and CSGI II (-) scored the best in terms of improving the stiffness of the canvas. Subjective evaluations of the darkening and whitening effects of the products on linen canvasses were consistent with the analytical measurements, with subjective perceptions and $L^{*}$ value changes correlating both for darkening and whitening effects.

In conclusion, from the conservation point of view the most promising products are ZFB 2a, ZFB $2 \mathrm{~b}$ and CSGI II (-). CNF also has potential given its good stiffening effect and the fact that it is completely cellulosebased (no other component is added) and is therefore highly compatible with canvasses.

\section{Abbreviations}

CMC: Carboxymethyl cellulose; CNC: Cellulose nanocrystals; CNF: Cellulose nanofibrils; CUT: Chalmers University of Technology, Sweden; CSGI: Consorzio Interuniversitario per lo Sviluppo a Grande Interfase, Florence, Italy; HEMC: Hydroxyethyl methylcellulose; PEl: Polyethylenimine; SCl: Specular Component Included; UB: University of Barcelona, Spain; ZFB: Zentrum für Bucherhaltung $\mathrm{GmbH}$, Leipzig, Germany.

\section{Acknowledgements}

Fátima Roces and Àlex Sánchez are gratefully acknowledged for their assistance in some of the final experimental analyses ( $\mathrm{pH}$, colour and drying time).

\section{Authors' contributions}

MOF conceived and designed the experiments, led the team's work, applied the products to the samples, analysed colour and wrote the first draft of the paper. GCF conceived and designed the experiments, applied the products to the samples, analysed gloss and designed and applied the star diagram evaluation. ANT produced mock-up samples and analysed gloss. CRR produced mock-up samples and analysed colour. IBM analysed pH. All authors contributed to data interpretation and corrected the manuscript. All authors read and approved the final manuscript. 


\section{Funding}

This research was funded by the European Union's Horizon 2020 Research and Innovation Programme under Grant Agreement No. 646063 (NanoRestArt).

\section{Availability of data and materials}

The datasets used and analysed in the current study are available from the corresponding author upon reasonable request.

\section{Competing interests}

The authors declare that they have no competing interests.

Received: 30 September 2019 Accepted: 18 February 2020

Published online: 26 February 2020

\section{References}

1. Padfield T. The deterioration of cellulose. In: Problems of conservation in museums = Problèmes de conservation dans les musées: a selection of papers presented to the joint meeting of the ICOM Committee for Museum Laboratories and the ICOM Committee for the Care of Paintings, held in Washington and New York. Paris; France: Éditions Eyrolles; 1969. p. 110-64.

2. Phenix A. The lining of paintings: traditions, principles and developments. In: Lining and backing: the support of paintings, paper and textiles: papers delivered at the UKIC Conference, 7-8 November 1995. 1995. p. 21-33.

3. Stoner $\mathrm{JH}$, Rushfield RA. The conservation of easel paintings. Abingdon: Routledge; 2012.

4. Giorgi R, Dei L, Ceccato M, Schettino C, Baglioni P. Nanotechnologies for conservation of cultural heritage: paper and canvas deacidification. Langmuir. 2002;18(21):8198-203.

5. Percival-Prescott W. The lining cycle. In: Conference on comparative lining techniques, National Maritime Museum, Greenwich, London, 23, 24 \& 25 April 1974. Greenwich; United Kingdom: National Maritime Museum (Great Britain); 1974.

6. Percival-Prescott W. Foreword. In: Lining paintings. In: Papers from the Greenwich Conference on Comparative Lining Techniques (1974). Archetype in association with the National Maritime Museum, Greenwich; 2003.

7. Ackroyd P, Villers C. Increasing minimalism. In: Bustin M, Caley T, editors. Alternatives to lining. The structural treatment of paintings on canvas without lining. London: UKIC; 2003. p. 9-14.

8. Bonfatti AM, Rossi E, Sardella A, Scicolone GC, Seves A, Testa G. Indagine sugli effetti del consolidamento di supporti cellulosici tessili a diversi stadi di degradazione. Kermes. 1995;22:11-7.

9. De Luca D. I manufati dipinti su supporto tessile. Vademecum per allievi restauratori. II Prato; 2012. p. 127

10. Bergeon S. "Science et patience" ou la restauration des peintures. Editions de la Réunion des musées nationaux; 1990. Paris. p. 266.

11. Sánchez Ortiz A. Restauración de obras de arte: pintura de caballete. Madrid: Akal; 2012.

12. Borgioli L, Cremonesi P. Le resine sintetiche usate nel trattamento di opere policrome. Padova: II Prato; 2005.

13. Horie CV. Materials for conservation: organic consolidants, adhesives and coatings. Oxford: Architectural Press; 2010.

14. Chelazzi D, Chevalier A, Pizzorusso G, Giorgi R, Menu M, Baglioni P. Characterization and degradation of poly(vinyl acetate)-based adhesives for canvas paintings. Polym Degrad Stab. 2014;107:314-20.

15. Cataldi A, Berglund L, Deflorian F, Pegoretti A. A comparison between micro- and nanocellulose-filled composite adhesives for oil paintings restoration. Nanocomposites. 2015;1(4):195-203.

16. Down JL. Adhesive compendium for conservation. In: Down JL, editor. Ottawa: Canadian Conservation Institute; 2015.

17. Berger GA, Russell WH. Conservation of paintings: research and innovations. London: Archetype Publications Ltd.; 2000.

18. Calvini P, Grosso V, Hey M, Rossi L, Santucci L. Deacidification of paper-a more fundamental approach. Pap Conserv. 1988;12(1):35-9.

19. Porck HJ. Mass deacidification: an update on possibilities and limitation. Amsterdam and Washington: European Commission on Preservation and Access and Commission on Preservation and Access; 1996.

20. Boone, T, Kidder, K, Russick, S. Bookkeeper ${ }^{\circledR}$ for spray use in single item treatments. The Book and Paper Group Annual 17; 1998.
21. Strlič M, Kolar J. Ageing and stabilisation of paper. Ljubljana: National and University Library; 2005.

22. Blüher, A, Grossenbacher, G. Save paper! Mass deacidification, today's experiences - tomorrow's perspectives. In: Papers given at the International Conference, 15-17 February 2006 Swiss National Library; 2006.

23. Baty JW, Maitland CL, Minter W, Hubbe MA, Jordan-Mowery SK. Deacidification for the conservation and preservation of paper-based works: a review. BioResources. 2010;5(3):1955-2023.

24. Baglioni P, Chelazzi D, Giorgi R. Nanotechnologies in the conservation of cultural heritage. A compendium of materials and techniques. Berlin: Springer; 2015.

25. Alexopoulou I, Zervos S. Paper conservation methods: an international survey. J Cult Herit. 2016;21:922-30.

26. Hackney S, Ernst T. The applicability of alkaline reserves to painting canvases. In: Preventive conservation: practice, theory and research Preprints of the contributions to the Ottawa Congress, 12-16 September 1994. International Institute for Conservation of Historic and Artistic Works; 1994. p. 223-7.

27. Baglioni P, Chelazzi D, editors. Nanoscience for the conservation of works of art. RSC Pub.; 2013. p. 495.

28. ECCO. European Confederation of Conservator-Restorer'Organisations Professional Guidelines II: Code of Ethics. Brussels: ECCO; 2003.

29. Sequeira S, Casanova C, Cabrita EJ. Deacidification of paper using dispersions of $\mathrm{Ca}(\mathrm{OH}) 2$ nanoparticles in isopropanol. Study of efficiency. J Cult Herit. 2006;7(4):264-72.

30. Baglioni M, Bartoletti A, Bozec L, Chelazzi D, Giorgi R, Odlyha M, et al. Nanomaterials for the cleaning and $\mathrm{pH}$ adjustment of vegetable-tanned leather. Appl Phys A. 2016;122(2):114.

31. Bridarolli A, Nechyporchuk O, Odlyha M, Oriola M, Bordes R, Holmberg $K$, et al. Nanocellulose-based materials for the reinforcement of modern canvas-supported paintings. Stud Conserv. 2018;63(sup1):332-4.

32. Kolman K, Nechyporchuk O, Persson M, Holmberg K, Bordes R. Combined nanocellulose/nanosilica approach for multiscale consolidation of painting canvases. ACS Appl Nano Mater. 2018;1 (5):2036-40.

33. Nechyporchuk O, Kolman K, Bridarolli A, Odlyha M, Bozec L, Oriola M, et al. On the potential of using nanocellulose for consolidation of painting canvases. Carbohydr Polym. 2018;194:161-9.

34. Böhme N, Anders M, Reichelt T, Schuhmann K, Bridarolli A, Chevalier A. New treatments for canvas consolidation and conservation. Herit Sci. 2020;8:16. https://doi.org/10.1186/s40494-020-0362-y.

35. Poggi G, Toccafondi N, Chelazzi D, Canton P, Giorgi R, Baglioni P. Calcium hydroxide nanoparticles from solvothermal reaction for the deacidification of degraded waterlogged wood. J Colloid Interface Sci. 2016:473:1-8.

36. Oriola-Folch M. Non-destructive condition assessment of painting canvases using NIR spectrometry. PhD Thesis [Internet]. Barcelona: University of Barcelona; 2012. http://diposit.ub.edu/dspace/handle/2445/125243. Cited 20 Sept 2019

37. Hanson AR. Measurement good practice guide No. 94. Good practice guide for measurement of gloss. UK: National Physical Laboratory; 2006 p. 86

38. Strlic M, Kolar J, Kocar D, DrnovsekT, Selih V, Susic R, et al. What is the $\mathrm{pH}$ of alcaline paper? e-Preservation Sci. 2004;1:35-47.

39. Hedley $\mathrm{G}$. The practicalities of the interaction of moisture with oil paintings on canvas. In: Villers C, editor. Measured opinions: collected papers on the conservation of paintings: Gerry Hedley. London: United Kingdom Institute for Conservation; 1993. p. 112-22.

40. Phenix A. Effects of organic solvents on artists' oil paint films: swelling. In: Mecklenburg, Marion F, Charola, Elena A, Koestler RJ, editor. New Insights into the Cleaning of Paintings: Proceedings from the Cleaning 2010 International Conference, Universidad Politecnica de Valencia and Museum Conservation Institute. Smithsonian Contributions to Museum Conservation. Washington, DC: Smithsonian Institution; 2010. p. 69-76.

41. Mokrzycki W, Tatol M. Color difference delta E-a survey. Mach Graph Vis. 2011;20(4):383-411.

\section{Publisher's Note}

Springer Nature remains neutral with regard to jurisdictional claims in published maps and institutional affiliations. 